\title{
Article
}

\section{Pathologic Characteristics of Pregnancy-Related Meningiomas}

\author{
Laura Giraldi ${ }^{1,+}$, Emma Kofoed Lauridsen ${ }^{2,+}$, Andrea Daniela Maier ${ }^{2,3}{ }^{(0)}$, Jørgen Vinsløv Hansen ${ }^{1}$, \\ Helle Broholm ${ }^{3}$, Kåre Fugleholm ${ }^{2}$, David Scheie ${ }^{3}(\mathbb{D})$ and Tina Nørgaard Munch ${ }^{1,2,4, *(\mathbb{D})}$ \\ 1 Department of Epidemiology Research, Statens Serum Institute, DK-2300 Copenhagen, Denmark; \\ lvfg@ssi.dk (L.G.); jvha@ssi.dk (J.V.H.) \\ 2 Department of Neurosurgery, Copenhagen University Hospital, DK-2100 Copenhagen, Denmark; \\ emma.lauridsen@regionh.dk (E.K.L.); andrea.maier@regionh.dk (A.D.M.); \\ kaare.fugleholm.buch@regionh.dk (K.F.) \\ 3 Department of Pathology, Copenhagen University Hospital, DK-2100 Copenhagen, Denmark; \\ helle.broholm@regionh.dk (H.B.); david.scheie@regionh.dk (D.S.) \\ 4 Department of Clinical Medicine, University of Copenhagen, DK-2100 Copenhagen, Denmark \\ * Correspondence: tina.noergaard.munch@regionh.dk \\ + Shared first-authorship.
}

check for updates

Citation: Giraldi, L.; Lauridsen, E.K.; Maier, A.D.; Hansen, J.V.; Broholm, H.; Fugleholm, K.; Scheie, D.; Munch, T.N. Pathologic Characteristics of Pregnancy-Related Meningiomas Cancers 2021, 13, 3879. https:// doi.org/10.3390/cancers13153879

Academic Editor: David Wong

Received: 24 June 2021

Accepted: 29 July 2021

Published: 1 August 2021

Publisher's Note: MDPI stays neutral with regard to jurisdictional claims in published maps and institutional affiliations.

Copyright: (c) 2021 by the authors. Licensee MDPI, Basel, Switzerland. This article is an open access article distributed under the terms and conditions of the Creative Commons Attribution (CC BY) license (https:// creativecommons.org/licenses/by/ $4.0 /)$.
Simple Summary: Meningiomas are the most common primary intracranial tumor in adults. Meningiomas are usually benign and slow growing. Treatment is surgical resection in the case of symptomatic growth. Dramatic growth can occur during pregnancy, complicating clinical management and entailing a risk to the well-being of the mother and fetus. Authors of a previous review paper raised the hypothesis that prolactin may be a key contributor to the sudden growth seen in pregnancyrelated meningiomas. We set out to investigate the presence of prolactin receptors/prolactin, as well as other female hormones and histopathological characteristics of pregnancy-related meningiomas in Denmark, compared to meningiomas from female controls within the same age group. No differences in hormone receptor distribution were found between the groups and very few meningiomas expressed prolactin receptors, which contradicts the above-mentioned hypothesis. Interestingly, we observed above cut-point proliferative indices of the meningiomas for the entire study population of females in the reproductive age.

Abstract: Meningiomas are the most common intracranial tumor. During pregnancy, explosive growth of a known meningioma occasionally occurs, but the underlying reasons remain unknown. Prolactin has been suggested as a possible key contributor to pregnancy-related meningioma growth This study sets out to investigate prolactin and prolactin receptor status in 29 patients with pregnancyrelated meningiomas in Denmark, from January 1972 to December 2016, as compared to 68 controls aged 20-45 years, also undergoing resection of a meningioma. Furthermore, we investigated potential differences in the progesterone and estrogen receptor statuses, WHO grade, Ki-67 labeling indices, and locations of the resected meningiomas between the cases and controls. Immunohistochemical analyses were performed, and histopathology and intracranial location were assessed with the investigator blinded for the case-control status. None of the samples stained positive for prolactin and very few samples stained positive for prolactin receptors, equally distributed among cases and controls. Estrogen and progesterone receptors generally followed the same distributional pattern between groups, whereas above cut-point Ki-67 labeling indices for both groups were observed. In conclusion, our results did not support the notion of prolactin as a key contributor to pregnancyrelated meningioma growth. Rather, the similarities between the cases and controls suggest that meningiomas early in life may comprise a distinct biological entity.

Keywords: meningioma; pregnancy-related meningioma; prolactin receptor; progesterone receptor; estrogen receptor; Ki-67 


\section{Introduction}

Meningioma (WHO Grades I-III) is the most common extra-axial, intracranial tumor. Meningiomas originate from arachnoid cap cells and may require surgical resection if the lesion is symptomatic and surgically accessible. The occurrence of meningioma is $5 / 100,000 /$ year with an overweight observed in females [1]. The peak ratio of female to male incidence is 3.15 among those aged $35-44$ years [2]. The age-specific incidence rate of meningioma is increasing throughout life, peaking at an incidence rate of 40/100,000 amongst women over the age of 85 years in the United States [3]. Only two known risk factors have been identified: neurofibromatosis type 2 and cranial ionizing radiation $[1,4,5]$. Female hormones have been suggested as a possible risk factor. However, several previous cohort studies found limited evidence of associations between female hormonal factors, such as parity, hormone replacement therapy, early menarche, and the occurrence of meningiomas [6-18]. It is well known that meningiomas express hormone receptors, but the composition of these varies. Up to $88 \%$ of meningiomas are progesterone receptor positive, $40 \%$ are estrogen receptor positive, and 39\% are positive for androgen receptors [19].

The well-known phenomenon of explosive growth of an already known meningioma that occurs in some women during pregnancy remains puzzling [20-22]. A review points out that pregnancy-related meningiomas are more likely to be located near the pituitary gland than other meningiomas [23]. The authors speculate that meningiomas supplied by the anterior circulation may be exposed to prolactin. Prolactin passes through the fenestrated capillaries and the portal system, which is unique for the hypophyseal gland, and is possibly carried by the adjacent vessels along their natural paths, exposing nearby cells to high concentrations. Pregnancy-related accelerated growth is mainly observed during the second and third trimesters, which coincides temporally with increasing prolactin levels, thus supporting this notion [24-26]. Pregnancy-related meningiomas were more often of chordoid (6\%) or clear-cell types (4\%) [23], as compared to meningiomas in the background population, which were $0.5 \%$ [27] and $0.2 \%$ [28], respectively. Combined with the findings that $40-60 \%$ of meningiomas are prolactin receptor-positive [23], the authors raise the hypothesis that meningioma growth during pregnancy may be affected by prolactin.

The arguments underlying the hypothesis are (1) prolactin is secreted by the anterior pituitary gland [29], (2) the plasma concentration of prolactin during pregnancy reaches its peak at term [30], (3) prolactin accelerates the proliferation rate of meningioma-derived cells in vitro [31-33], (4) prolactin is both a circulating hormone and paracrine/autocrine factor participating in angiogenesis [34], which is important in the tumorigenesis process of, for example, meningiomas [35], and (5) prolactin has a pivotal role in osmoregulation in various cells and tissues [36,37]. It is speculated that this last feature could be responsible for the rapid changes in meningioma volume, which can be observed during and after pregnancy [23]. In summary, there are currently three underlying prolactin-related theories of drastic meningioma volume changes observed during and after pregnancy: angiogenesis, osmotic regulation and proliferative activity.

The Ki-67/MIB-1 monoclonal antibody is a marker of tumor proliferative activity correlating with histopathological malignancy grade [38] and is widely used in pathologic grading of meningiomas, affecting both diagnosis and prognosis [38]. In a literature study [38] from 2010, Ki-67 labeling indices were $4 \%, 8 \%$ and $17 \%$ for meningiomas WHO Grades I-III, respectively. A labeling index over $4 \%$ was associated with an increased recurrence rate [39]. In the aforementioned review in pregnancy-related meningiomas, a mean Ki-67 labeling index of $6.63 \%$ was found [23].

Studies investigating prolactin receptor status in meningiomas resected from pregnant or lactating women could not be found in the literature, possibly due to the extremely rare occurrence. The four neuropathology units in Denmark have stored tissue from all resected CNS tumors in Denmark since the 1970s, which provides the opportunity of investigating meningioma tissue removed from this patient group in a nation-wide case-control study. This will, by far, be the largest sample of pregnancy-related meningiomas as compared to previous studies. 
The prolactin hypothesis described above proposes several distinct features of pregnancyrelated meningiomas as compared to meningiomas from female controls aged 20-45 from the background population. The specific aims of this study were to investigate if pregnancyrelated meningiomas were characterized by (1) specific histopathological features, (2) a higher expression of prolactin receptors and prolactin, (3) increased Ki-67 labeling index, and (4) the location of meningiomas in the skull-base area in close proximity to the pituitary gland. As secondary outcomes, the expression of estrogen and progesterone receptors were investigated.

\section{Materials and Methods}

\subsection{Data Sources}

The following registers were used:

The Civil Registration System (CRS) has existed since 1968 and is continuously updated with demographic information [40]. Every individual in Denmark is given a personal CPR-number, which allows interlacement of the different registers.

The National Patient Register (NPR) has registered all hospital admittances using the International Classification of Diseases (ICD-10) since 1977. Since 1995, emergency room visits, and outpatient contacts have been registered as well [41].

The Danish Cancer Registry (DCR) contains ICD-10 as well as histologic diagnoses of all types of cancer as defined in the WHO classification systems [42].

The Danish Pathology Register (DPR) was established in 1997 when all pathology departments in Denmark were legally obliged to report pathology data to the National Board of Health. Since 1999, DPR has been updated daily from the The National Danish Pathology Data Bank (DPDB) [43].

The National Danish Pathology Data Bank (DPDB) was established in 1999. Departments of pathology record all pathology data online to the DPDB, using guidelines published by the National Board of Health. Historical pathology data has been added to the database and, for a few departments, data from the early 1970s can be obtained [43].

\subsection{Study Design}

Retrospective observational study.

\subsection{Study Population}

The study population consisted of women aged 20-45 years, who underwent resection of an intracranial meningioma during the period of 1 January 1972 to 31 December 2016, identified from the NPR, DCR, and DPR. Cases were women with pregnancy-related meningiomas who underwent operation during the study period. Pregnancy-related meningiomas were defined as meningiomas from women who underwent surgical resection no more than nine months before the date of giving birth and no later than 12 months after the date of giving birth. This time window was based on the normal duration of a pregnancy and the period of possible postpartum lactation. A randomly selected subset of women aged 20-45 years who underwent resection of a meningioma unrelated to pregnancy during the study period were used as controls. After cases and controls were identified in the registers, all available meningioma tissue samples were retrieved from the DPDB.

\subsection{Exposure}

Prolactin and pregnancy-related changes in the secretion of progesterone and estrogen. In terms of their pregnancy and the following period of possible lactation, the cases were exposed to much higher doses of prolactin than the control group [44].

\subsection{Outcome}

The primary outcome was positive immunohistochemical stains for the prolactin receptor and prolactin. Secondary outcomes were positive immunohistochemical stains 
for estrogen and progesterone, as well as Ki-67 labeling indices above cut-points for the respective WHO Grades I-III.

\subsection{Pathology}

Upon receival of the tissue samples and immunohistochemistry, the hematoxylin and eosin (HE) tissue stains were reviewed by a senior neuropathologist who evaluated which sample was most representative. Based on this, one sample per patient was chosen. The tissue samples were re-evaluated by two senior neuropathologists (HB, DS), according to the 2016 WHO classification and histopathological subtypes. The meningothelial and transitional subtypes were reported as a combined group since the two senior neuropathologists considered the distinguishment highly subjective. Furthermore, the distinction between meningothelial and transitional subtypes are of no clinical significance, with both subtypes belonging to WHO Grade I. The observers were blinded with regards to which patient and group (case/control) the pathology specimen belonged to.

The tissue samples were examined with immunohistochemical analyses for prolactin receptor (PRL-R), prolactin (PRL), estrogen receptor (ER), progesterone receptor (PR), and the Ki-67 labeling index.

\subsection{Immunohistochemistry}

The blocks were cut into $4 \mu \mathrm{m}$ sections and fixated on glass. The PR staining was performed with BenchMark ULTRA incubation with a PGR antibody ((1E2), Roche 7902223 Ventana Medical Systems, Basel, Switzerland) for $32 \mathrm{~min}$. The positive control for PR was breast tissue. The ER staining was performed with BenchMark ULTRA, using an ER antibody ((SP1), Roche 790-2223 Ventana Medical Systems, Basel, Switzerland) and incubated for $32 \mathrm{~min}$. The positive control for ER was breast tissue. The PRL-R staining was performed with BenchMark ULTRA incubation with a prolactin receptor antibody ((B6.2 + PRLR742) Abcam) for $30 \mathrm{~min}$. The positive control for the PRL-R was a prolactin receptor positive prolactinoma. The PRL staining was performed with BenchMark ULTRA incubation with a prolactin antibody (poly, Roche 790-2223 Ventana Medical Systems, Basel, Switzerland) for $32 \mathrm{~min}$. The positive control for PRL was the pituitary gland.

For the Ki-67 staining, tissue was incubated with mouse monoclonal anti-Ki-67 antibody (clone MIB-1 dilution 1:50, Agilent GA626 Dako Denmark A/S Glostrup). A standardized immunostaining procedure used an automated immunostainer (Dako Amnis, Agilent). The tissue samples were pre-heated $\left(30 \mathrm{~min}\right.$ at $\left.97^{\circ} \mathrm{C}\right)$ and a peroxidase blocking agent was added after primary antibody incubation $(20 \mathrm{~min}$.) The positive controls included human tonsil, colon or liver tissue.

\subsection{Assessment of Tumor Labeling Index}

The entire pathology specimen was systematically examined for PRL-R and PRL staining, using the $\times 40$ lens. Tumor cells with a perinuclear stain were considered positive for PRL-R, even though stained cells were only found in dispersed solitary whorls.

ER expression was grouped in accordance with the American Society of Clinical Oncology/College of American Pathologists guidelines for breast cancer [45], where a $\geq 1 \%$ cut-off is considered positive. Therefore, specimens with $\geq 1 \%$ of unequivocally stained nuclei were placed in the "+" category. If over $50 \%$ of cells in a specimen were stained or multiple cells were heavily stained, these samples were placed in the category "++". Samples without ER staining were placed in the "-" category.

PR expression was divided into one of four categories by examining the full meningioma pathology specimen, using the $\times 40$ lens: $0-25 \%, 25-50 \%, 50-75 \%$ and $75-100 \%$.

Ki-67 was quantified by systematic examination of the entire pathology specimen and detection of stained hotspots. By viewing the hotspot using the $\times 40$ lens, a hundred cells were counted, and the number of stained cells were expressed as the resulting percentage. 


\subsection{Statistical Analysis}

For all levels of all categorical outcomes, the two-tailed Fisher's exact test was used to test if the probability of being classified with a given level of positivity was the same for cases and controls. Within each level of WHO grade, a $t$-test allowing for unequal variances was used to test if means of the continuous outcome, the Ki-67 labeling index, was similar between cases and controls. A $p$-value of $<0.05$ was considered statistically significant. SAS 9.4 was used for data management and statistical analysis.

\subsection{Ethics Statement}

The study has been approved by the Danish Data Protection Agency and by the Regional Committees on Health Research Ethics in the Capital Region of Denmark (Journal No. H-18023804).

\section{Results}

\subsection{Characteristics}

A total of 37 cases and 86 controls were identified from the National Patient Register and the Cancer Registry during the period 1 January 1972 to 31 December 2016. Tumor tissue could not be retrieved for eight cases and 18 controls, which resulted in a study population consisting of 29 women who underwent surgical resection of a meningioma during pregnancy or during the lactating period (up to 12 months after date of giving birth) and 68 females aged 20-45 who also underwent resection of a meningioma, but unrelated to pregnancy. Age at the time of surgery was not markedly different between cases and controls; the median age of the cases was 36 years, and the median age of the controls was 33 years. The majority of pregnancy-related meningiomas $(76 \%)$ occurred in relation to first- or second-born child. Figure 1 presents the temporal distribution of pregnancy-related meningioma surgeries during pregnancy and the postpartum period.

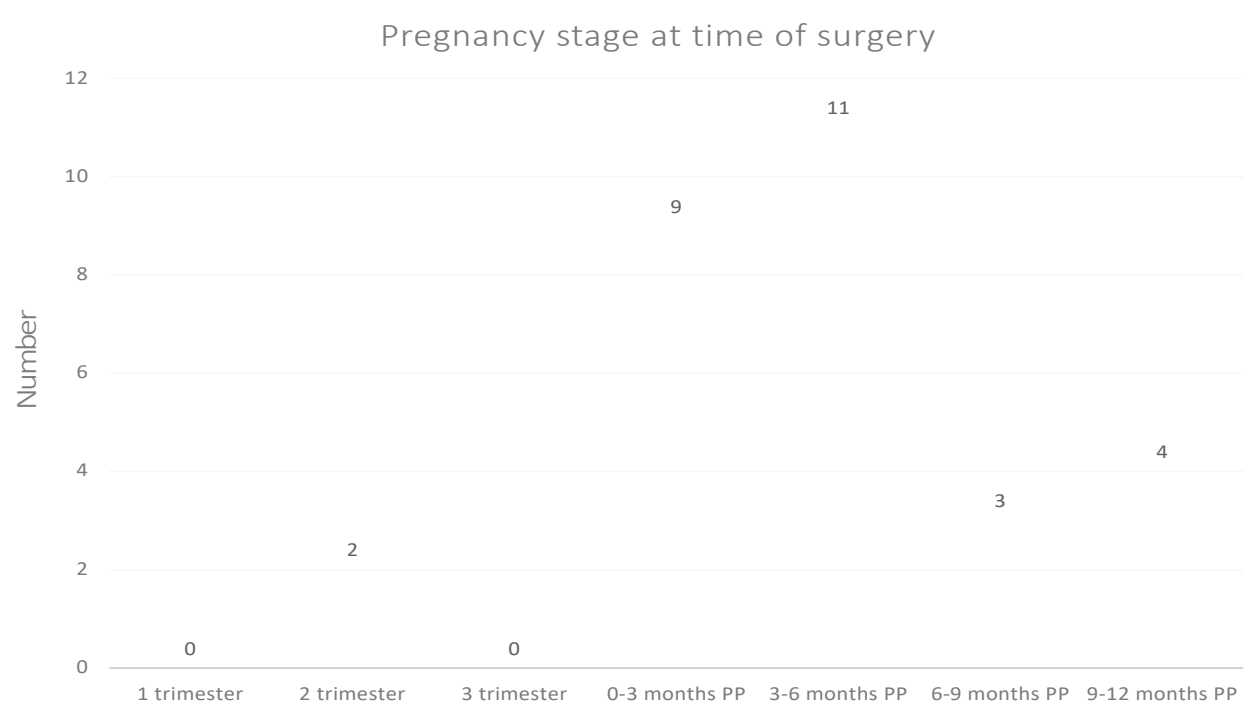

Figure 1. Temporal distribution of pregnancy-related meningioma surgeries in relation to pregnancy and postpartum period. $\mathrm{PP}=$ postpartum.

\subsection{Pathology}

3.2.1. WHO Grades (I-III), Ki-67 Labeling Index and Histopathological Subtypes

Table 1 presents the distribution of pregnancy-related meningiomas and controls, according to the WHO grade, Ki-67 labeling index and histopathological subtype. A total of $89.7 \%$ of the pregnancy-related meningiomas were WHO Grade I and $10.3 \%$ were WHO Grade II (none were WHO Grade III). Of the controls, $83.8 \%$ were WHO Grade I, 13.2\% were WHO Grade II and 2.9\% were WHO Grade III. 
Table 1. WHO Grades (I-III), Ki-67 labeling index, and histopathological subtypes of pregnancyrelated meningiomas and controls.

\begin{tabular}{|c|c|c|c|}
\hline & $\begin{array}{c}\text { Pregnancy-Related } \\
\text { Meningiomas }(\mathrm{N}=29) \\
\text { N (\%) }\end{array}$ & $\begin{array}{c}\text { Controls }(\mathrm{N}=68) \\
\mathrm{N}(\%)\end{array}$ & $p$-Value $* *$ \\
\hline \multicolumn{4}{|c|}{ WHO Grade } \\
\hline I & $26(89.7)$ & $57(83.8)$ & 0.54 \\
\hline II & $3(10.3)$ & $9(13.2)$ & 1.00 \\
\hline III & $0(0)$ & $2(2.9)$ & 1.00 \\
\hline \multicolumn{4}{|c|}{ Ki-67 labeling index (\%) } \\
\hline WHO Grade I & $6.3(6.0)$ & $6.5(5.0)$ & 0.88 \\
\hline WHO Grade II & $4.3(2.9)$ & $11.3(7.4) *$ & 0.043 \\
\hline WHO Grade III & NA & $15.5(13.4)$ & NA \\
\hline \multicolumn{4}{|c|}{ Histopathological subtype } \\
\hline Meningothelial/Transitional & $18(62.1)$ & $42(61.8)$ & 1.00 \\
\hline Fibrous & $5(17.2)$ & $11(16.2)$ & 1.00 \\
\hline Microcystic & $3(10.3)$ & $1(1.5)$ & 0.079 \\
\hline Angiomatous & $0(0)$ & $1(1.5)$ & 1.00 \\
\hline Metaplastic & $0(0)$ & $1(1.5)$ & 1.00 \\
\hline Secretory & $0(0)$ & $1(1.5)$ & 1.00 \\
\hline Chordoid & $1(3.4)$ & $1(1.5)$ & 0.51 \\
\hline Clear cell & $1(3.4)$ & $0(0)$ & 0.30 \\
\hline Atypical & $1(3.4)$ & $8(11.8)$ & 0.27 \\
\hline Papillary & $0(0)$ & $1(1.5)$ & 1.00 \\
\hline Rhabdoid & $0(0)$ & $1(1.5)$ & 1.00 \\
\hline
\end{tabular}

Regarding the $\mathrm{Ki}-67$ labeling index, the average values in the pregnancy-related meningiomas WHO Grade I was 6.3\%, whereas the average for WHO grade II was $4.3 \%$ (three cases only). In the control group, the average Ki-67 values for WHO Grades I-III were $6.5 \%, 11.3 \%$ and $15.5 \%$ respectively.

Regarding the histopathological subtypes in the pregnancy-related meningiomas, $62.1 \%$ were meningothelial or transitional, which was similar to the controls $(61.8 \%)$. Among the cases, $17.2 \%$ harbored fibrous meningiomas, which was found in $16.2 \%$ of controls. Microcystic meningiomas were found in $10.3 \%$ of cases but only $1.5 \%$ of controls. With regards to chordoid and clear cell meningiomas, which are of special interest, we found one of each among the cases, each corresponding to $3.4 \%$.

\subsubsection{Hormone Receptor Status}

Table 2 presents the expression of prolactin, prolactin receptors, estrogen receptors and progesterone receptors in cases and controls. Among pregnancy-related meningiomas, $6.9 \%$ expressed meningioma cells positive for prolactin receptors, compared to $2.9 \%$ of controls $(p=0.58)$. Positive meningioma cells were rare and widely dispersed, with a strong, perinuclear staining, as shown in Figure 2. No cases nor controls displayed positivity for PRL. 
Table 2. Expression of prolactin, prolactin receptors, estrogen receptors and progesterone receptors in pregnancy-related meningiomas and controls.

\begin{tabular}{|c|c|c|c|c|}
\hline Receptor Type & & $\begin{array}{c}\text { Pregnancy-Related } \\
\text { Meningiomas (N = 29) } \\
\text { N (\%) }\end{array}$ & $\begin{array}{c}\text { Controls }(\mathrm{N}=68) \\
\mathrm{N}(\%)\end{array}$ & $p$-Value \\
\hline $\begin{array}{l}\text { Prolactin } \\
\text { receptor }\end{array}$ & & $2(6.9)$ & $2(2.9)$ & 0.58 \\
\hline Prolactin & & $0(0)$ & $0(0)$ & 1.00 \\
\hline \multirow{3}{*}{ Estrogen * } & - & $21(72.4)$ & $57(83.8)$ & 0.26 \\
\hline & + & $8(27.6)$ & $9(13.2)$ & 0.14 \\
\hline & ++ & $0(0)$ & $2(2.9)$ & 1.00 \\
\hline \multirow{4}{*}{ Progesterone ** } & $0-25 \%$ & $4(14.3)$ & $14(20.9)$ & 0.57 \\
\hline & $25-50 \%$ & $4(14.3)$ & $6(9.0)$ & 0.47 \\
\hline & $50-75 \%$ & $3(10.7)$ & $10(14.9)$ & 0.75 \\
\hline & $75-100 \%$ & $17(60.7)$ & $37(55.2)$ & 0.66 \\
\hline
\end{tabular}

*In the " - " group, there was no ER expression. In the " + " group, a cut-off value of $>1 \%$ of ER expression was used, and in the " ++ " group, either $>50 \%$ of cells expressed ER receptors or many cells were considered heavily stained. ${ }^{* *}$ In one case and one control, the progesterone staining was considered insufficient, and thus these were excluded from the results. ${ }^{\#}$ Estimated by Fisher's exact test.

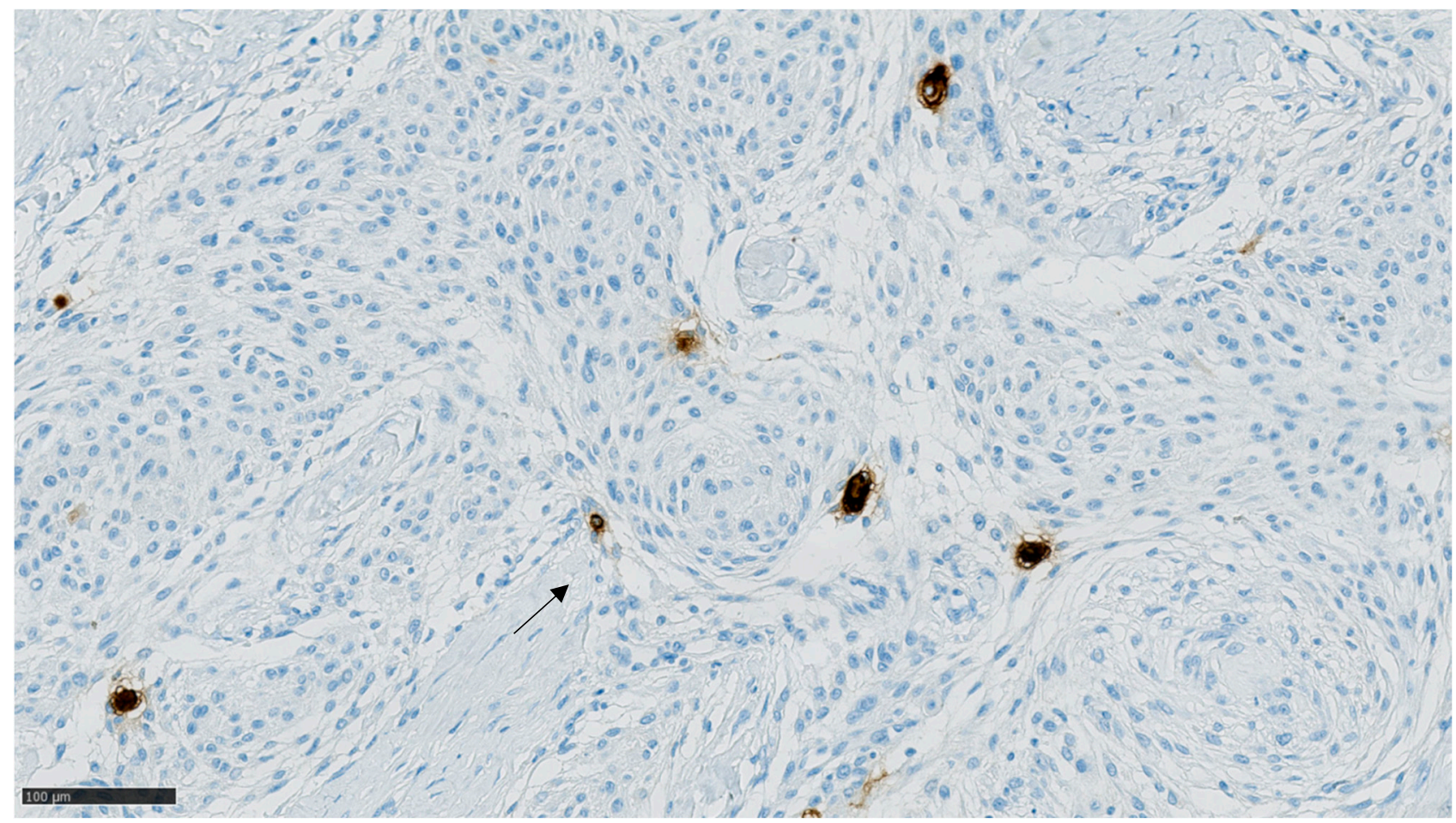

Figure 2. PRL-R staining in case at $\times 200$ magnification. A few, dispersed tumor cells showed a strong, perinuclear stain.

The estrogen receptor was overall positive in $27.6 \%$ of cases and $16.2 \%$ of controls, of which $27.6 \%$ of cases and $13.2 \%$ of controls were above the cut-point of $\geq 1 \%$ positive meningioma cells $(p=0.14)$. None of the pregnancy-related meningiomas were above the cut-point of $>50 \% /$ many heavily stained cells, which applied only to very few of the controls $(2.9 \%)$.

The distribution of progesterone receptor expression in the cases was not significantly different from the controls. The staining patterns are presented in Figures 2-4. 


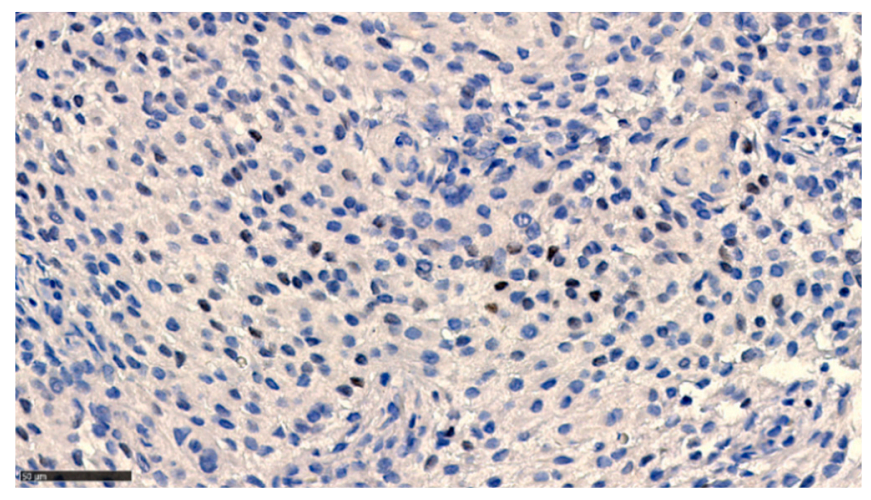

(a)

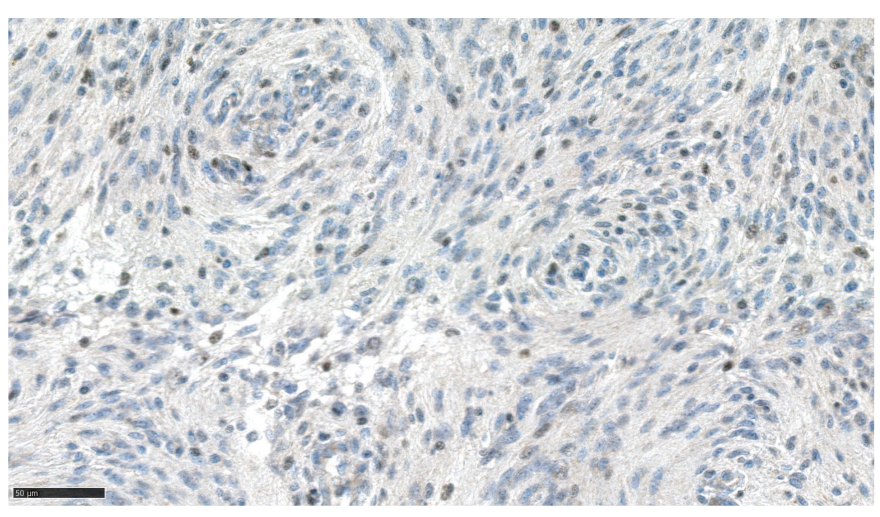

(b)

Figure 3. Estrogen receptor staining in meningioma tissue from (a) control and (b) case, both belonging to the " + " category at a $\times 400$ magnification.

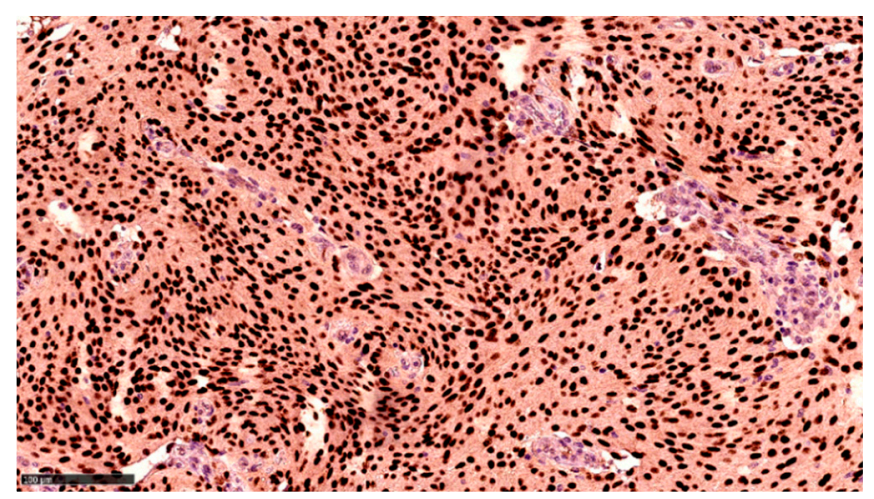

(a)

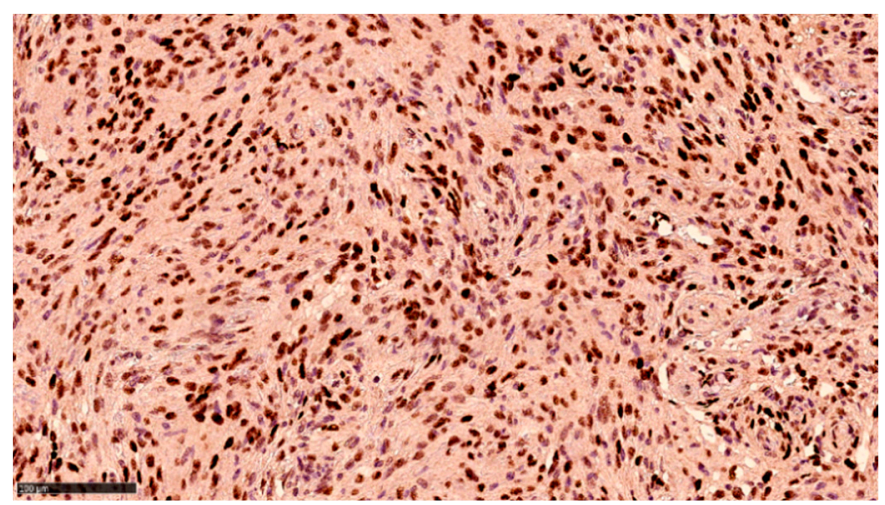

(b)

Figure 4. Progesterone receptor staining from (a) control and (b) case, both belonging to the 75-100\% group at $\times 200$ magnification.

\subsection{Meningioma Location}

As previous studies suggest some association between intracranial location and the likelihood of hormonal impact on growth [23], we investigated the intracranial location for the subset of the study population in which this information was available. Thus, the meningioma locations by proximity to the pituitary gland, the location according to the major anatomical intracranial regions, are presented in Table 3.

No major differences were seen, however, of the pregnancy-related meningiomas; almost $60 \%$ of cases were located in the frontal/parasellar region, compared to $40 \%$ in controls ( $p=0.044$ ), whereas only $3.4 \%$ of the meningiomas from cases were located in the occipital region or posterior fossa, compared to $22 \%$ of the meningiomas from controls $(p=0.034)$. 
Table 3. The meningioma location by frontal/parasellar location, and according to the major anatomical intracranial regions.

\begin{tabular}{|c|c|c|c|}
\hline $\begin{array}{l}\text { Location by Proximity to the } \\
\text { Pituitary Gland }\end{array}$ & $\begin{array}{c}\text { Pregnancy-Related } \\
\text { Meningiomas (N = 29) } \\
\text { N (\%) }\end{array}$ & $\begin{array}{c}\text { Controls } \\
(\mathrm{N}=68) \\
\mathrm{N}(\%)\end{array}$ & $p$-Value $\#$ \\
\hline Frontal/parasellar region* & $17(58.6)$ & $24(35.3)$ & 0.044 \\
\hline Other $* *$ & $2(6.9)$ & $17(25.0)$ & 0.051 \\
\hline No information & $10(34.5)$ & $27(39.7)$ & 0.66 \\
\hline \multicolumn{4}{|l|}{$\begin{array}{l}\text { Location according to the major } \\
\text { anatomical intracranial regions }\end{array}$} \\
\hline $\begin{array}{l}\text { A: Frontoparietal, olfactory groove, } \\
\text { "fossa anterior" and frontal convexity }\end{array}$ & $7(24.1)$ & $16(23.5)$ & 1.00 \\
\hline $\begin{array}{l}\text { B: Sphenoid wing, suprasellar, } \\
\text { temporofrontal and tuberculum sellae }\end{array}$ & $10(34.5)$ & $10(14.7)$ & 0.052 \\
\hline C: Occipital and fossa posterior & $1(3.4)$ & $15(22.1)$ & 0.034 \\
\hline No information & $11(37.9)$ & $27(39.7)$ & 1.00 \\
\hline
\end{tabular}

* Frontal/parasellar region: fossa anterior, frontal, frontoparietal, sphenoid wing, OGM, opticus, sella, temporofrontal, clinoideus anterior, orbita. ${ }^{* *}$ Other: ventricles, occipital, CPV, fossa media, parietal, posterior, sinus transversus, temporal, trigeminus. ${ }^{\#}$ Estimated by Fisher's exact test.

\section{Discussion}

In this case-control study including the majority of patients with pregnancy-related meningiomas in Denmark 1972-2016, we investigated the presence of prolactin and the prolactin receptor status in the resected meningiomas, compared to meningiomas from female controls within the same age group. Furthermore, we investigated potential differences in the progesterone- and estrogen-receptor status, WHO grade, histopathological subtype, Ki67 labeling indices and intracranial location of the resected meningiomas between the cases and controls. None of the samples stained positive for prolactin and very few meningioma cells stained positive for prolactin receptors, being equally distributed among pregnancyrelated meningiomas and meningiomas from controls. Estrogen and progesterone receptors generally followed the same distributional pattern between groups, whereas above cutpoint Ki-67 labeling indices for both cases and controls were observed. Thus, our results did not support the notion of prolactin being a key contributor to pregnancy-related meningioma growth. Rather, the similarities between the cases and controls may indicate that meningiomas displaying growth early in life constitute a distinct biological entity.

\subsection{Pregnancy Stage and Replication History}

In this study, surgery was most often performed within 6 months postpartum (Figure 1). According to the previously mentioned review on pregnancy-related meningiomas, most of the meningiomas were diagnosed during the second and third trimesters of pregnancy [23]. As surgeries are preferentially carried out postpartum, it is possible that some of the meningiomas might have been diagnosed during pregnancy. Thus, the risks of surgery during pregnancy may very well account for the peak of surgeries in the first six months postpartum observed in this study. As we only had access to brain imaging studies for a minority of the patients, the exact time of diagnosis in our study population could not be investigated.

\subsection{Pathology and Ki-67 Labeling Index}

The distribution of benign and atypical meningiomas (WHO Grades I and II) were not significantly different between pregnancy-related meningiomas and the meningiomas from controls (Table 1). Notably, no malignant meningiomas were found among cases. Anaplastic (WHO Grade III) meningiomas constitute 1.0-2.8\% of intracranial meningiomas [46], yet we found $15.5 \%$ among controls in the same age group. The higher occurrence of anaplastic meningiomas amongst this rather young population is noteworthy; however, it is based on a small number of patients. 
Like Laviv et al., we found occurrence of the rare chordoid and clear-cell types of meningiomas ( $3.4 \%$ of each) among the pregnancy-related meningiomas. There may be a tendency toward overrepresentation in pregnancy-related meningiomas, considering the occurrences in the background population of $0.5 \%$ [27] and $0.2 \%$ [28], respectively. However, due to the small sample size, no firm conclusions about possible overrepresentation of chordoid and clear-cell meningiomas can be drawn. Furthermore, $10.3 \%$ of the pregnancyrelated meningiomas were microcystic, compared to $1.5 \%$ among controls. Microcystic meningiomas share many similarities with clear-cell meningiomas [23].

The mean Ki-67 index in pregnancy-related meningiomas Grades I-II were $6.3 \%$ and $4.3 \%$, respectively, which is in line with the mean Ki-67 index reported by Laviv et al. of $6.63 \%$ [23]. In our control group, mean Ki-67 labeling indices for meningiomas with WHO Grades I-III were $6.5 \%, 11.3 \%$ and $15.5 \%$, respectively. These Ki-67 labeling indices are slightly higher than the reported general cut-off values of $4 \%, 8 \%$ and $17 \%$ for meningiomas of WHO Grades I, II, and III, respectively [38]. A Ki-67 labeling index over $4 \%$ has been described as a risk factor for recurrence of meningiomas [39]. This raises the hypothesis that not only pregnancy-related meningiomas, but perhaps also meningiomas in younger individuals in general, may have a higher proliferative activity than other meningiomas.

\subsection{Hormone Receptor Status}

Only $6.9 \%$ and $1.5 \%$ of pregnancy-related meningiomas and controls expressed prolactin receptors $(p=0.58)$ in tumor cells. None of the samples stained positive for prolactin. These findings contradict the otherwise interesting and plausible hypothesis raised by Laviv et al., namely that prolactin drives meningioma growth during pregnancy, [23] as a greater amount of prolactin receptor positivity would have been expected in the pregnancyrelated meningiomas. Furthermore, the few and widely dispersed PRL-R positive cells seem insufficient to account for meningioma volume changes by prolactin receptor-binding. Using more sensitive methods for detection of hormone receptor expression may be warranted in future studies.

These modest findings are also surprising in light of the previously reported prolactin receptor expression in up to $40-60 \%$ of meningiomas $[32,33,47,48]$. However, these studies utilized different methods for the detection of prolactin receptors, e.g., binding assays $[32,33,47]$. One study detected prolactin receptors in meningiomas by immunohistochemical methods, using a different antibody (clone PRL02; Neomarkers, Fremont, CA, USA) [48].

Thus, the lack of prolactin receptor expression and prolactin in meningioma cells makes prolactin an unlikely key contributor to the sudden growth seen in some pregnancyrelated meningiomas, at least through the mechanism of prolactin-prolactin receptor binding. Laviv et al. also suggested that prolactin may contribute to mechanisms of angiomatous and edematous growth. However, no prolactin was discovered in the meningioma cells in this study. To our knowledge, there is no established association between prolactinoma and meningioma development or growth. In such cases, patients may be exposed to much higher concentrations of prolactin.

Our results regarding progesterone and estrogen receptor positivity are consistent with the reported expression of progesterone receptors in $88 \%$ of meningiomas from the general population and estrogen receptor expression in 40\% [19]. No significant differences in estrogen and progesterone receptor distribution between cases and controls were found.

\subsection{Meningioma Location}

A cornerstone in the hypothesis of prolactin-driven growth proposed by Laviv et al. is the location of pregnancy-related meningiomas. It was reported that meningiomas often have an anterior circulation blood supply. Information on the location of the meningiomas was available for $64 \%$ of this study population. Although not available for all, we do believe the proportion with available information is representative of the entire study population, as the lack of information is purely due to administrative causes. Similar to 
Laviv et al., who found that $68 \%$ of pregnancy-related meningiomas were found in the combined hypophyseal-sphenoid-olfactory region, we observed that meningiomas from cases were more prone to have similar locations (Table 3). One could ask the question of whether this indicates the influence of another pituitary hormonal factor. We did not investigate the presence of all the other pituitary hormone receptors, which could be the scope of a future study.

\subsection{Limitations and Strengths of Study}

An important limitation of this study is that the study involved old paraffin blocks; hence, we did not always know which fixation medium was used. This could potentially have influenced the immunohistochemical staining.

This is the first nationwide investigation on pathological characteristics of the largest sample of pregnancy-related meningiomas to date. As pregnancy-related meningiomas are uncommon, it is highly valuable that departments of pathology have stored tissue samples, as this makes it possible to study a larger, unselected population.

\section{Conclusions}

In conclusion, the results of this study do not support the notion of prolactin being a key contributor to the sudden growth observed in some meningioma patients during pregnancy. Interestingly, both cases and controls displayed higher Ki-67 labeling indices than the cut-points of the respective $\mathrm{WHO}$ grades. Adding the fact that the cases and controls displayed fairly similar hormone receptor profiles and histopathological characteristics, altogether, they suggest that meningiomas from female patients in the reproductive age constitute a distinct biological entity in which a subset are prone to rapid growth. In general, neoplastic disease at a young age points toward a genetic predisposition. Future studies should be directed at elucidating the genetic and epigenetic characteristics of meningiomas among younger individuals in general.

Author Contributions: The contributions of the authors were as follows. Conceptualization, T.N.M.; methodology, H.B., D.S., J.V.H., T.N.M., and L.G.; validation, H.B. and D.S.; formal analysis, L.G., E.K.L., A.D.M., J.V.H.; investigation, E.K.L. and L.G.; resources, L.G.; data curation, J.V.H.; writingoriginal draft preparation, E.K.L., L.G. and T.N.M.; writing-review and editing, all authors; visualization, A.D.M.; supervision, T.N.M., K.F., H.B., D.S. and A.D.M.; project administration, L.G. and E.K.L.; funding acquisition, L.G. All authors have read and agreed to the published version of the manuscript.

Funding: This research was funded by The Lundbeck Foundation (grant R249-2017-178), Dagmar Marshalls Fond, and Aase og Ejnar Danielsens Fond.

Institutional Review Board Statement: The study was conducted according to the guidelines of the Declaration of Helsinki and approved by the Research Ethics Committee of the Capital Region of Denmark (H-18023804).

Informed Consent Statement: Patient consent was waived since only tissue stored in an existing biobank was used, and the study did not reveal any findings of importance for prognosis or clinical course of the meningioma patients. Data were not presented in a manner enabling identification of individual persons.

Data Availability Statement: The data presented in this study are available on request from the corresponding author. The data are not publicly available due to restrictions from the Danish Data Protection Agency.

Acknowledgments: We would like to thank the Departments of Pathology at Aarhus University Hospital and Odense University Hospital for selecting and sending the fixated tissues. We would also like to express our gratitude to the following departments for sending relevant tissue blocks: Copenhagen University Hospital, Glostrup Hospital, Hvidovre Hospital, Herlev Hospital and Aalborg University Hospital. We would like to thank the Department of Pathology at Copenhagen University Hospital for handling the tissues and conducting the immunohistochemical staining. 
Conflicts of Interest: The authors declare no conflict of interest. The funders had no role in the design of the study; in the collection, analyses, or interpretation of data; in the writing of the manuscript, or in the decision to publish the results.

\section{References}

1. Christine, M.; Marco, H.; Karl, R.; Michele, R.; Milena, S.; Elena, M.; Charles, V. Meningioma. Crit. Rev. Oncol. Hematol. 2008, 67, 153-171. [CrossRef]

2. Wiemels, J.; Wrensch, M.; Claus, E.B. Epidemiology and etiology of meningioma. J. Neuro-Oncol. 2010, 99, 307-314. [CrossRef] [PubMed]

3. Claus, E.B.; Black, P.M.; Bondy, M.L.; Calvocoressi, L.; Schildkraut, J.M.; Wiemels, J.L.; Wrensch, M. Exogenous hormone use and meningioma risk. Cancer 2007, 110, 471-476. [CrossRef]

4. $\quad$ Preston, D.L.; Ron, E.; Yonehara, S.; Kobuke, T.; Fujii, H.; Kishikawa, M.; Tokunaga, M.; Tokuoka, S.; Mabuchi, K. Tumors of the nervous system and pituitary gland associated with atomic bomb radiation exposure. J. Natl. Cancer Inst. 2002, 94, 1555-1563. [CrossRef]

5. Ron, E.; Modan, B.; Boice, J.D.; Alfandary, E.; Stovall, M.; Chetrit, A.; Katz, L. Tumors of the Brain and Nervous System after Radiotherapy in Childhood. N. Engl. J. Med. 1988, 319, 1033-1039. [CrossRef]

6. Anic, G.M.; Madden, M.H.; Nabors, L.B.; Olson, J.J.; LaRocca, R.V.; Thompson, Z.J.; Pamnani, S.J.; Forsyth, P.A.; Thompson, R.C.; Egan, K.M. Reproductive factors and risk of primary brain tumors in women. J. Neuro-Oncol. 2014, 118, 297304. [CrossRef] [PubMed]

7. Claus, E.B.; Calvocoressi, L.; Bondy, M.L.; Wrensch, M.; Wiemels, J.L.; Schildkraut, J.M. Exogenous hormone use, reproductive factors, and risk of intracraniel meningioma in females. J. Neurosurg. 2014, 118, 649-656. [CrossRef] [PubMed]

8. Custer, B.; Longstreth, W.T.; Phillips, L.E.; Koepsell, T.D.; Van Belle, G. Hormonal exposures and the risk of intracranial meningioma in women: A population-based case-control study. BMC Cancer 2006, 6, 152. [CrossRef] [PubMed]

9. Hatch, E.E.; Linet, M.S.; Zhang, J.; Fine, H.A.; Shapiro, W.R.; Selker, R.G.; Black, P.M.; Inskip, P.D. Reproductive and hormonal factors and risk of brain tumors in adult females. Int. J. Cancer 2004, 114, 797-805. [CrossRef] [PubMed]

10. Korhonen, K.; Raitanen, J.; Isola, J.; Haapasalo, H.; Salminen, T.; Auvinen, A. Exogenous sex hormone use and risk of meningioma: A population-based case-control study in Finland. Cancer Causes Control 2010, 21, 2149-2156. [CrossRef]

11. Lee, E.; Grutsch, J.; Persky, V.; Glick, R.; Mendes, J.; Davis, F. Association of meningioma with reproductive factors. Int. J. Cancer 2006, 119, 1152-1157. [CrossRef] [PubMed]

12. Preston-Martin, S.; Monroe, K.; Lee, P.J.; Bernstein, L.; Kelsey, J.; Henderson, S.; Forrester, D.; Henderson, B. Spinal meningiomas in women in Los Angeles County: Investigation of an etiological hypothesis. Cancer Epidemiol. Biomark. Prev. 1995, 4, $333-339$.

13. Wigertz, A.; Lönn, S.; Hall, P.; Auvinen, A.; Christensen, H.C.; Johansen, C.; Klaeboe, L.; Salminen, T.; Schoemaker, M.; Swerdlow, A.; et al. Reproductive Factors and Risk of Meningioma and Glioma. Cancer Epidemiol. Biomarkers Prev. 2008, 17, 2663-2670. [CrossRef]

14. Lambe, M.; Coogan, P.; Baron, J. Reproductive factors and the risk of brain tumors: A population-based study in Sweden. Int. J. Cancer 1997, 72, 389-393. [CrossRef]

15. Benson, V.S.; Pirie, K.; Green, J.; Bull, D.; Casabonne, D.; Reeves, G.K.; Beral, V.; for the Million Women Study Collaborators. Hormone replacement therapy and incidence of central nervous system tumours in the Million Women Study. Int. J. Cancer 2010, 127, 1692-1698. [CrossRef]

16. Wigertz, A.; Lönn, S.; Mathiesen, T.; Ahlbom, A.; Hall, P.; Feychting, M. Risk of Brain Tumors Associated with Exposure to Exogenous Female Sex Hormones. Am. J. Epidemiol. 2006, 164, 629-636. [CrossRef]

17. Benson, V.S.; for the Million Women Study Collaborators; Pirie, K.; Green, J.; Casabonne, D.; Beral, V. Lifestyle factors and primary glioma and meningioma tumours in the Million Women Study cohort. Br. J. Cancer 2008, 99, 185-190. [CrossRef] [PubMed]

18. Blitshteyn, S.; Crook, J.E.; Jaeckle, K.A. Is There an Association Between Meningioma and Hormone Replacement Therapy? J. Clin. Oncol. 2008, 26, 279-282. [CrossRef] [PubMed]

19. Korhonen, K.; Salminen, T.; Raitanen, J.; Auvinen, A.; Isola, J.; Haapasalo, H. Female predominance in meningiomas can not be explained by differences in progesterone, estrogen, or androgen receptor expression. J. Neuro-Oncol. 2006, 80, 1-7. [CrossRef] [PubMed]

20. Bickerstaff, E.R.; Small, J.M.; Guest, I.A. The relapsing course of certain meningiomas in relation to pregnancy and menstruation. J. Neurol. Neurosurg. Psychiatry 1958, 21, 89-91. [CrossRef]

21. Michelsen, J.J.; New, P.F. Brain tumour and pregnancy. J. Neurol. Neurosurg. Psychiatry 1969, 32, 305-307. [CrossRef] [PubMed]

22. Wahab, M.; Al-Azzawi, F. Meningioma and hormonal influences. Climacteric 2003, 6, 285-292. [CrossRef] [PubMed]

23. Laviv, Y.; Ohla, V.; Kasper, E.M. Unique features of pregnancy-related meningiomas: Lessons learned from 148 reported cases and theoretical implications of a prolactin modulated pathogenesis. Neurosurg. Rev. 2016, 41, 95-108. [CrossRef]

24. Kanaan, I.; Jallu, A.; Kanaan, H. Management Strategy for Meningioma in Pregnancy: A Clinical Study. Semin. Neurol. 2003, 13, 197-204. [CrossRef] [PubMed]

25. Moscovici, S.; Fraifeld, S.; Cohen, J.E.; Dotan, S.; Elchalal, U.; Shoshan, Y.; Spektor, S. Parasellar Meningiomas in Pregnancy: Surgical Results and Visual Outcomes. World Neurosurg. 2014, 82, e503-e512. [CrossRef]

26. Roelvink, N.C.A.; Kamphorst, W.; Van Alphen, H.A.M.; Rao, B.R. Pregnancy-Related Primary Brain and Spinal Tumors. Arch. Neurol. 1987, 44, 209-215. [CrossRef] 
27. Couce, M.E.; Aker, F.V.; Scheithauer, B.W. Chordoid Meningioma: A clinicopathologic study of 42 cases. Am. J. Surg. Pathol. 2000, 24, 899-905. [CrossRef]

28. Jain, D.; Sharma, M.C.; Sarkar, C.; Suri, V.; Garg, A.; Singh, M.; Sharma, B.S.; Mahapatra, A.K. Clear cell Meningioma, an uncommon variant of meningioma: A clinicopathologic study of nine cases. J. Neuro-Oncol. 2006, 81, 315-321. [CrossRef] [PubMed]

29. Gregerson, K. ProlactinStructure, Function, and Regulation of Secretion. Knobil Neill's Physiol. Reprod. 2006, 1, 1703-1726. [CrossRef]

30. Abbassi-Ghanavati, M.; Greer, L.; Cunningham, F. A Reference Table for Clinicians. Obstet. Gynecol. 2009, 114, 1326-1331. [CrossRef]

31. Boyle-Walsh, E.; Shenkin, A.; White, M.C.; Fraser, W.D. Effect of glycoprotein and protein hormones on human meningioma cell proliferation in vitro. J. Endocrinol. 1995, 145, 155-161. [CrossRef]

32. Jimenez-Hakim, E.; El-Azouzi, M.; Black, P.M. The effect of prolactin and bombesin on the growth of meningioma-derived cells in monolayer culture. J. Neuro-Oncol. 1993, 16, 185-190. [CrossRef] [PubMed]

33. Muccioli, G.; Ghè, C.; Faccani, G.; Lanotte, M.; Forni, M.; Ciccarelli, E. Prolactin receptors in human meningiomas: Characterization and biological role. J. Endocrinol. 1997, 153, 365-371. [CrossRef] [PubMed]

34. Corbacho, A.M.; De La Escalera, G.M.; Clapp, C. Roles of prolactin and related members of the prolactin/growth hormone/placental lactogen family in angiogenesis. J. Endocrinol. 2002, 173, 219-238. [CrossRef]

35. Barresi, V. Angiogenesis in meningiomas. Brain Tumor Pathol. 2011, 28, 99-106. [CrossRef] [PubMed]

36. Breves, J.P.; McCormick, S.D.; Karlstrom, R.O. Prolactin and teleost ionocytes: New insights into cellular and molecular targets of prolactin in vertebrate epithelia. Gen. Comp. Endocrinol. 2014, 203, 21-28. [CrossRef] [PubMed]

37. Loretz, C.A.; Bern, H.A. Prolactin and Osmoregulation in Vertebrates. An update. Neuroendocrinology 1982, 35, $292-304$. [CrossRef] [PubMed]

38. Abry, E.; Thomassen, I.; Salvesen, O.; Torp, S.H. The significance of Ki-67/MIB-1 labeling index in human meningiomas: A literature study. Pathol. Res. Pract. 2010, 206, 810-815. [CrossRef] [PubMed]

39. Liu, N.; Song, S.-Y.; Jiang, J.-B.; Wang, T.-J.; Yan, C.-X. The prognostic role of Ki-67/MIB-1 in meningioma: A systematic review with meta-analysis. Medicine 2020, 99, e18644. [CrossRef] [PubMed]

40. Pedersen, C.B. The Danish Civil Registration System. Scand. J. Public Health 2011, 39, 22-25. [CrossRef]

41. Lynge, E.; Sandegaard, J.L.; Rebolj, M. The Danish National Patient Register. Scand. J. Public Health 2011, 39, 30-33. [CrossRef]

42. Gjerstorff, M.L. The Danish Cancer Registry. Scand. J. Public Health 2011, 39, 42-45. [CrossRef]

43. Bjerregaard, B.; Larsen, O.B. The Danish Pathology Register. Scand. J. Public Health 2011, 39, 72-74. [CrossRef]

44. Hu, Y.; Ding, Y.; Yang, M.; Xiang, Z. Serum prolactin levels across pregnancy and the establishment of reference intervals. Clin. Chem. Lab. Med. 2017, 56, 803-807. [CrossRef]

45. Hammond, M.E.H.; Hayes, D.F.; Dowsett, M.; Allred, D.C.; Hagerty, K.L.; Badve, S.; Fitzgibbons, P.; Francis, G.; Goldstein, N.S.; Hayes, M.; et al. American Society of Clinical Oncology/College of American Pathologists Guideline Recommendations for Immunohistochemical Testing of Estrogen and Progesterone Receptors in Breast Cancer. J. Clin. Oncol. 2010, 28, 2784-2795. [CrossRef]

46. Modha, A.; Gutin, P.H. Diagnosis and Treatment of Atypical and Anaplastic Meningiomas: A Review. Neurosurgery 2005, 57, 538-550. [CrossRef] [PubMed]

47. Ciccarelli, E.; Razzore, P.; Gaia, D.; Todaro, C.; Longo, A.; Forni, M.; Ghè, C.; Camanni, F.; Muccioli, G.; Faccani, G.; et al. Hyperprolactinaemia and prolactin binding in benign intracranial tumours. J. Neurosurg. Sci. 2001, 45, 70-74. [PubMed]

48. Leães, C.G.S.; Filho, A.P.; Lima, J.F.P.; Dallago, C.M.; Batista, R.; Barbosa-Coutinho, L.M.; Ferreira, N.P.; Oliveira, M.D.C. Hyperprolactinemia and immunohistochemical expression of intracellular prolactin and prolactin receptor in primary central nervous system tumors and their relationship with cellular replication. Brain Tumor Pathol. 2007, 24, 41-46. [CrossRef] [PubMed] 